\title{
A diez años del golpe de Estado del 15 de octubre de 1979
}

Hace diez años que el movimiento insurreccional de la Juventud Militar, depuso al entonces presidente de la república General Carlos Humberto Romero y posibilitó la instalación de una Junta Revolucionaria de Gobierno, la cual estaba formada por los Coroneles Adolfo Majano y Abdul Gutierrez y los civiles Dr. Guillermo Ungo, Dr. Román Mayorga Quiróz y el Ing. Mario Andino. El objetivo y la intención que perseguia la Junta era establecer las bases para un verdadero desarrollo económico social y político en El Salvador.

La Proclama de la Fuerza Armada del 15 de octubre de 1979, planteaba la justificación del movimiento insurreccional y parecia establecer un nuevo papel para los militares en el contexto de la realidad. Los problemas que identificaban en la Proclama eran los siguientes: violación de los derechos humanos; fomento y tolerancia a la corrupción en la administración pública y de justicia; desprestigio del país y de la institución armada; los escandalosos fraudes electorales; adopción de programas inadecuados de desarrollo, en los que los tímidos cambios de estructuras habian sido frenados por el poder económico y político de sectores conservadores, etc. Parecian estar convecidos de que !os problemas de El salvador son "producto de ariticuadas estructuras económicas, sociales y políticas que han prevalecido tradicionalmente en el país, las que no ofrecen para la mayoria de los habitantes las condiciones mínimas necesarias para que puedan realizarce como seres humanos. Por otra parte, la corrupción y la falta de capacidad del régimen, habian provocado desconfianza en el sector privado, por lo que cientos de millones de colones se fugaban del país acentuándose así la crisis económica en perjuicio de los sectores populares".

Ciertamente la identificación de estos problemas llevo a la necesidad de establecer un programa de emergencia el cual incluia una serie de 
lineamientos y medidas como: I. El cese de la violencia y la corrupción para lo cual se hacia efectiva la disolución de ORDEN y se erradicarian las prácticas corruptas de la administración pública y de justicia; II. Garantizar la vigencia de los derechos humanos, creando un ambiente propicio para elecciones verdaderamente libres, fortaleciedo el sistema democrático y permitiendo la constitución de partidos de toda ideología, amnistia general a presos políticos y exilados, respeto al derecho de sindicalización en todos los sectores y a la libre emisión del pensamiento; III. Adoptar medidas que conduzcan a una distribución equitativa de la riqueza nacional, incrementando al mismo tiempo, en forma acelerada, el producto territorial bruto, para lo cual se señalaba la necesidad de iniciar un proceso de reforma agraria, reformas en el sector financiero, tributario y de comercio exterior, adopción de medidas de protección al consumidor para contrarestar los efectos de la inflación, crear programas de desarrollo que aumenten la producción y la generación de fuentes adicionales de empleo, reconocer y garantizar el derecho a la vivienda, alimentación, educación y salud de todos los habitantes, y garantizar la propiedad privada en función social. IV. Encauzar en forma positiva las relaciones externas del país, para lo cual consideraban importante restablecer las relaciones con Honduras, fortalecer las relaciones con Nicaragua, estrechar vínculos con Guatemala, Costa Rica y Panamá, establecer relaciones cordiales con todos los países del mundo y garantizar el cumplimiento de los compromisos internacionales adquiridos.

Ciertamente una vez conformada la Junta Revolucionaria de Gobierno y el gabinete, las reacciones desestabilizadoras de los sectores más conservadores del pais se hacian presentes ya que veian con inminencia la aplicación de medidas reformistas y la posibilidad de un mayor desarrollo de los sectores populares; los militares más vinculados a las estructuras de poder oligárquico veian también con preocupación las posibilidades que el nuevo gobierno los juzgara por las violaciones a los derechos humanos y por su incapacidad en la gestión pública. Todo esto llevo a serias contradicciones de la Junta con los sectores oligárquicos y los militares más reaccionarios lo cual se manifestaba tanto en el bloqueo de las medidas que la Junta deseaba tomar,asi como en la permanente represión que el ejercito y los cuerpos de seguridad aplicaban a los sectores populares. A su vez la Junta tampoco estaba excenta de contradicciones con las organizaciones populares de la izquierda, las cuales exigian la pronta implementación de medidas de cambio estructural y de otras medidas que favorecieran al pueblo salvadoreño. Estas contradicciones y problemas llevarian al final del año a la renuncia del gabinete de gobierno y posteriormente de 
los miembros civiles de la Junta; de esta forma las siguientes Juntas formadas a través del pacto entre la Democracia Cristiana y los Militares evidenciaban ya las debilidaes para impulsar un proyecto verdaderamente democratico y popular.

La Democracia Cristiana despues de 10 años considera que si ella no hubiera asumido el reto de incorporarce al gobierno en el año de 1980, la cantidad de muertos producto de la represión y de la guerra sucia hubiera sido mayor a las más de 70 mil victimas que a la fecha se consideran, a su vez no se habria logrado las reformas economicas, "el proceso democrático" y la mayor libertad de expresión.

En base a estos aspectos considerados tanto en la Proclama de la Fuerza Armada del 15 de octubre, asi como en la visión de la Democracia Cristiana, trataremos de evaluar cual es la situación que prevalece en EI Salvador despues de estos 10 años.

En cuanto a la vigencia de los derechos humanos, el cese de la violencia y de la corrupción, estos años nos han demostrado con tristeza que estos fenómenos se han agudizado, la guerra sucia impulsada por los sectores de ultraderecha y sus escuadrones de la muerte, por los cuerpos de seguridad y el ejército han provocado la mayor cantidad de víctimas de las más de 70 mil que han sido asesinadas, desaparecidas y masacradas; la guerra como expresión de los graves problemas no resueltos se ha profundizado a lo largo de estos años. Los desplazados internos suman más de medio millón de personas, los refugiados en el exterior alcanzan más de 600 mil personas; los desaparecidos y la represión a los miembros de las organizaciones populares, sindicales, universitarias, magisteriales, campesinas, etc., es un hecho frecuente evidenciando el irrespeto al derecho de organización, de movilización y libre expresión del pensamiento. El gran logro plantedo por el Gobierno Demócrata Cristiano de la democratización del país es relativo, ya que lo que tenemos es una democracia formal y no una democracia real. Como dirian algunos se han "abierto espacios políticos" pero no podemos hablar de una verdadera democracia ya que existen graves violaciones a los derechos humanos, a la organización y a las libertades políticas; lo que parece estar a la base de esta concepción de democratización es el que se hayan desarrollado varios procesos electorales tanto para alcaldes, diputados y presidenciales. Pero las elecciones no reflejan una amplia parlicipación de los distintos sectores, ya que las elecciones han sido de "las derechas y para las derechas", los partidos políticos de izquierda han estado marginados durante casi todo este periodo.

En cuanto a lograr una distribución equitativa del ingreso y un 
crecimiento del producto nacional, durante estos 10 años la crisis económica y la pobreza extrema en la que se encuentra una gran mayoría de la poblacióri se ha profundizado; así tenemos que a pesar de haberse desarrollado la reforma agraria con las limitaciones en cuanto al área afectada de tierras ( $15 \%$ del área agrícola nacional) y al número de beneficiarios ( 71000 familias), en el áre rural sigue existiendo una gran cantidad de familias sin acceso a la tierra y viviendo en condiciones muy precarias. Las nacionalizaciones del comercio exterior del café y el azúcar, que deberian haber permitido el traslado de los excedentes de la comercialización en beneficio del desarrollo nacional y de las grandes mayorias, han mostrado su inefectividad, producto de un manejo politizado e ineficiente de las distintas administraciones; permitiendo así en la actualidad, la contra reforma via liberalización de la comercialización de estos productos por el sector privado y la minimización de las acciones del INCAFE y el INAZUCAR en esta área tan importante. La nacionalización de la banca que durante el periodo siguió mostrando una estructura de asignación del crédito en beneficio de la gran empresa, de los productos de exportación y oreintado a préstamos de corto plazo, no cumplió con el concepto de democratización del crédito y de una efectividad real en el desarrollo económico y social, nuevamente la politización y el favoritismo a los sectores del gran capital fue la norma de su funcionamiento.

En relación a la crisis económica esta se ha profundizado en los últimos 10 años, de tal manera que el déficit externo supera en la actualidad los 450 millones de dólares, el "déficit fiscal es mayor a los 600 millones de colones y la inflación acumulada durante estos años es también superior al $175 \%$; mientras tanto los salarios reales se han deteriorado seriamente y el ingreso percápita esta a los niveles de los años 60 . La profunda recesión en la que se encuentra la economía salvadoreña no da muestras de revertirse, el producto interno bruto creció a una tasa promedio anual de $-1.6 \%$ durante estos años.

Por otra parte, la situación de extrema pobreza se ha agudizado, afectando en la actualidad a más del $40 \%$ de las familias, los servicios básicos para la población como salud, educación, vivienda, etc. se han deteriorado seriamente en cuanto a su cobertura y a su infraestructura. La guerra, durante estos años ha tenido un impacto serio sobre las condiciones económicas y sociales, los presupuestos del gobierno se destinan en gran proporción a las necesidades de guerra, limitando asi los recursos a las necesidades sociales; a su vez la guerra agudiza los desequilibrios económicos, y lo que es más grave en la actualidad no parece existir una voluntad real por resolver el conflicto por la via política, lo cual significa más destrucción y muerte en el futuro próximo. 
Por último en las relaciones externas desarrolladas por las sucesivas Juntas a partir de 1980 y los gobienos de Unidad Nacional, Demócrata Cristiano y el actual gobierno de ARENA, estuvo y está como prioridad la relativa subordinación de la política exterior a los intereses de la Administración norteamericana. No podemos negar que el restablecimiento de las relaciones con Honduras y los acuerdos de presidentes desde Esquipulas II son aspectos positivos en este periodo, pero mucho de la polita exterior implementada y especialmente en contra de Nicaragua, asi como el apoyo encubierto a la contra y otros aspectos de la política interna y de la política económica, fueron diseñados e impulsados por el gobieno norteamericano utilizando a los gobiernos salvadoreños en detrimento de la soberania nacional.

Por lo tanto, podemos concluir que despues de 10 anos del golpe de Estado del 15 de octubre de 1979, las causas que dieron origen a dicho golpe siguen vigentes, el movimiento insurreccional de la Juventud Militar y la Proclama de la Fuerza Armada fueron desvirtuados en su esencia a partir de 1980, dando paso asi a uno de los periodos más sangrientos y dramáticos de la historia del pais. Un periodo que se iniciaba con grandes posibilidades de encauzar la economía y la sociedad por el sendero del desarrollo, encuentra sus limites en las posiciones de los sectores conservadores, de militares sin visión de futuro, de un gobierno nortemericano preocupado por sus pseudo intereses geopolíticos y de políticos oportunistas. La actualidad marca el retorno de la derecha al gobierno y las posibilidades de revertir las reformas y de establecer nuevamente un proyecto político y económico a favor del gran capital y en detrimento de las grandes mayorias. De esta manera la paz con justicia social se presenta muy lejana y nos obliga a esforzarnos más por alcanzarla. 